\title{
Results From Wales' 2016 Report Card on Physical Activity for Children and Youth: Is Wales Turning the Tide on Children's Inactivity?
}

\author{
Richard Tyler, Marianne Mannello, Rebecca Mattingley, Chris Roberts, Robert Sage, Suzan R Taylor, \\ Malcolm Ward, Simon Williams, and Gareth Stratton
}

\begin{abstract}
Background: This is the second Active Healthy Kids Wales Report Card. The 2016 version consolidates and translates research related to physical activity (PA) among children and youth in Wales, and aims to raise the awareness of children's engagement in PA and sedentary behaviors. Methods: Ten PA indicators were graded using the Active Healthy Kids-Canada Report Card methodology involving a synthesis and expert consensus of the best available evidence. Results: Grades were assigned as follows: Overall PA, D+; Organized Sport Participation, $C$; Active and Outdoor Play, $C$; Active Transportation, $C$; Sedentary Behaviors, D-; Physical Literacy, INC; Family and Peer Influences, $D+$; School, $B$; Community and the Built Environment, $C$; and National Government Policy, Strategies, and Investments, $B$-. Conclusions: Despite the existence of sound policies, programs, and infrastructure, PA levels of children and youth in Wales are one of the lowest and sedentary behavior one of the highest globally. From the 2014 Report Card, the Family and Peer Influences grade improved from $D$ to $D+$, whereas Community and the Built Environment dropped from $B$ to $C$. These results indicate that a concerted effort is required to increase PA and decrease sedentary time in children and young people in Wales.
\end{abstract}

Keywords: health, sedentary, play, policy, community and environment, school

Wales has a population of approximately 3 million people of which $\sim 702,600$ are children and young people (0-19 years of age). ${ }^{1}$ The majority of children in Wales are insufficiently active leaving Wales in the bottom quartile globally for physical activity (PA) levels in school-aged children. ${ }^{2}$ Inequalities in PA also exist: twice as many boys are sufficiently active as girls, PA levels decline with age, differences exist between ethnic groups, and there is a social gradient where activity follows socioeconomic status. ${ }^{2}$ In addition, cardiorespiratory fitness levels of children in Wales are among the lowest in Europe. ${ }^{3}$ Further, recent data found that less than half of 30009 to 11 year old children assessed achieved a healthy level of overall health-related fitness. ${ }^{4}$ In addition, obesity levels of children in Wales are the highest in the $\mathrm{UK}^{5}$ and among the highest globally. ${ }^{2}$

Conversely, Wales has a good record of supporting PA through policies and strategies. For example, Sport Wales have a mission to get "every child hooked on sport for life,"6 and support this with an emphasis on physical literacy through physical education and sport

Tyler and Stratton are with the Applied Sports Technology Exercise and Medicine (A-STEM) Research Centre, College of Engineering, Swansea University, Bay Campus, Swansea, Wales, United Kingdom. Mannello is with Play Wales, Cardiff, Wales, United Kingdom. Mattingley is with Sport Wales, Cardiff, Wales, United Kingdom. Roberts is with the Social Research and Information Division, Welsh Government (and HBSC Wales Principal Investigator), Cardiff, Wales, United Kingdom. Sage and Ward are with Public Health Wales, Cardiff, Wales, United Kingdom. Taylor is with the Dept of Sport and Exercise Sciences, Wrexham Glyndwr University, Wrexham Campus, Wrexham, Wales, United Kingdom. Williams is with the Faculty of Life Sciences and Education, University of South Wales, Pontypridd, Wales, United Kingdom. Stratton (G.Stratton@Swansea.ac.uk) is corresponding author. programming. ${ }^{7}$ In 2001 Wales was the first country to make statute article 31 of the Convention on the Rights of the Child (UNCRC) recognizing the rights of children to play, ${ }^{8}$ and also the first country to have an Active Travel Act. ${ }^{9}$

This is the second Active Healthy Kids (AHK) Wales Report Card following the inaugural 2014 version (http://www.swansea. ac.uk/activehealthykidswales/). Swansea University coordinated the work, supported by a national network of academics and professionals from sport, play, transport, public health, sport and exercise science, and education sectors. These constituents formed the research working group (RWG).

The purpose of this manuscript is to summarize the findings of the AHK Wales 2016 Report Card. Data from a number of surveys collected from 2013-2015 were synthesized to assign grades to each quality indicator. Where available, data as far back as 2002 were used for the analysis of trends.

\section{Methods}

The RWG consisted of 11 members. The lead academic directed the development of the Report Card contents and RWG membership. The RWG comprised of the lead academic (GS), postgraduate researchers, academics, and professionals with expertise in PA and access to national data sources. The academic lead secured funding and outlined the program of work. The lead postgraduate researcher (RT) was responsible for data sourcing, synthesis and subsequent presentation to the RWG for interpretation, discussion and grading. The lead researcher was also responsible with the academic lead to produce the Report Card and web site materials. All members of the RWG collectively allocated grades to indicators. The methodology used was in accordance with the AHK Global Matrix ${ }^{10}$ and was used 
in RWG meetings to evaluate the synthesized summary statistics, make informed decisions and assign grades.

Ten indicators were assessed, an additional 2 (school and physical literacy) to the 8 included in the AHK Wales 2014 Report Card. School was added to be consistent with other countries and physical literacy ( 'the motivation, confidence, physical competence, knowledge and understanding to value and take responsibility for engagement in physical activities for life'), ${ }^{11}$ because of the emphasis placed on it by Sport Wales and the Education department of Welsh government. The indicators assessed were: 1) Overall Physical Activity Levels; 2) Organized Sport Participation; 3) Active and Outdoor Play; 4) Active Transportation; 5) Sedentary Behaviors; 6) Physical Literacy; 7) Family and Peer Influence; 8) School; 9) Community and the Built Environment; and 10) National Government Policy, Strategies, and Investments. A number of surveys were selected for sources of data in the current report card; these are presented in Table 1. The data sources used were the most recent (2013-2015) at the time of the grading process. In the first instance, surveys that were representative of children in Wales were selected. Where nationally representative data were not available the best available data were used. For the national government policy, strategy and investment indicator, a number of policy documents, strategy documents and other guidance that were publicly available were considered to inform the RWG during the grading process. ${ }^{21}$

The RWG met once a month to discuss, evaluate and critique data for each of the 10 indicators. During the meetings, data were reviewed in terms of representativeness of the survey, methodology of data collection, age range of participants, sample size, and the reporting of subgroups such as gender, age, disability and socioeconomic status. Commensurate with the AHK Global Matrix, ${ }^{10}$ specific benchmarks for each indicator and the grading framework of: $A$, we are succeeding with a large majority of children and youth ( $81 \%$ to $100 \%) ; B$, we are succeeding with well over half of children and youth (61\% to $80 \%)$; $C$, we are succeeding with about half of children and youth (41\% to $60 \%)$; $D$, we are succeeding with less than half, but some, children and youth (21\% to $40 \%) ; F$, we are succeeding with very few children and youth (0\% to 20\%), were used in assigning grades to each indicator. Grades were assigned a ' + ' or '-' to indicate a trend or inequality in the data. A consensus approach was used to reach a decision and assign a grade to each indicator.

\section{Results}

Grades assigned to each indicator by the RWG are presented in Table 2, and the front cover is illustrated in Figure 1. Results are discussed herein on an indicator basis.

\section{Overall Physical Activity Levels: D-}

Two nationally representative data sources were used to assign an Overall PA grade. Self report data showed that $15 \%$ of children and young people aged 11 to 15 years old met the recommendation of at least 60 minutes of moderate-to-vigorous intensity PA (MVPA) every day of the week. ${ }^{14}$ Further analysis revealed that boys (20\%) were more active than girls (11\%) across all age groups and socioeconomic status. Overall, there was little difference in MVPA by socioeconomic status (15\% low, $13 \%$ medium, $17 \%$ high) or geographic regions (17\% North, 16\% West, 17\% East, 15\% Southeast, $15 \%$ Central south). In terms of changes over time there was a small downward trend in MVPA between 2006 and 2014 (21\% in $2006,19 \%$ in $2010,15 \%$ in 2014). Proxy report (parent) data further showed that $35 \%$ of children aged 4 to 15 years participated in MVPA for at least 1 hour every day and, although gender differences persisted ( $40 \%$ of boys, $29 \%$ of girls), there was no significant change between 2007 and 2014. ${ }^{15}$ D- was assigned to Overall PA as the proportion of children sufficiently active was between $20 \%$ and $39 \%$ and inequalities existed between sub groups. There was no change in grade from the AHK Wales 2014 Report Card.

\begin{tabular}{|c|c|c|c|}
\hline Data Source & Sample Size & Age Range & Indicator* \\
\hline Sport Wales: SSS $(2015)^{12}$ & 115,398 children & $7-16$ & $2,3,4,7,8$ \\
\hline Sport Wales: FESS $(2015)^{13}$ & 4568 young people & $16-20+$ & 2 \\
\hline HBSC Wales $(2013 / 14)^{14}$ & 9055 children & $11-16$ & $1,4,5$ \\
\hline WHS $(2014)^{15}$ & 2800 children; 14,170 adults & $4-15 ; 16+$ & 1,7 \\
\hline NSW $(2014 / 15)^{16}$ & 14,285 parents of children & $1-15$ & 4,9 \\
\hline Sport Wales: AAS (2014) ${ }^{17}$ & 13,145 adults & $15+$ & 7 \\
\hline Sustrans Wales: HUS $(2014 / 15)^{18}$ & 4356 children & $7-16$ & 4 \\
\hline LVSO $(2015)^{19}$ & 724 children & $7-11$ & 3 \\
\hline Beth Nesa? I What Next? $(2015)^{20}$ & 5961 children \& young people & $3-18+$ & 9 \\
\hline Sport Wales: DC Report (2015) Unpublished & 1600 children & $11-12$ & 6 \\
\hline
\end{tabular}

Note. The grade for indicator 10 was allocated using documents and guidance not in this table.

Abbreviations: SSS, School Sport Survey; FESS, Further Education Sport Survey; HBSC, Health Behavior in School-aged Children; WHS, Welsh Healthy Survey; NSW, National Survey for Wales; AAS, Active Adult Survey; HUS, Hands Up Survey; LVSO, Little Voices Shouting Out; DC, Dragon Challenge.

* 1 = Overall Physical Activity Levels; $2=$ Organized Sport Participation; $3=$ Active and Outdoor Play; $4=$ Active Transportation; $5=$ Sedentary Behaviors; 6 = Physical Literacy (Physical Competence); 7 = Family and Peer Influence; $8=$ School; 9 = Community and the Built Environment; $10=$ National Government Policy, Strategies, and Investments. 
Table 2 Grades According to Physical Activity Indicator in the Active Healthy Kids Wales 2016 Report Card on Physical Activity for Children and Youth

\begin{tabular}{lc}
\hline Indicator & Grades \\
\hline Overall Physical Activity Levels & $D$ - \\
Organized Sport Participation & $C$ \\
Active and Outdoor Play & $C$ \\
Active Transportation & $C$ \\
Sedentary Behaviors & $D$ - \\
Physical Literacy (Physical Competence) & $I N C$ \\
Family and Peer Influence & $D+$ \\
School & $B$ \\
Community and the Built Environment & $C$ \\
National Government Policy, Strategies and Investments & $B$ - \\
\hline
\end{tabular}

Note. The grade for each indicator is based on the percentage of children and youth meeting a defined benchmark: $A$ is $81 \%$ to $100 \%$; $B$ is $61 \%$ to $80 \%$; $C$ is $41 \%$ to $60 \%, D$ is $21 \%$ to $40 \% ; F$ is $0 \%$ to $20 \%$; INC is Incomplete (inconclusive data).

\section{Organized Sport Participation: C}

In line with Sport Wales' vision, the proportion of children 'hooked on sport' (children who take part in sport on 3 or more occasions a week in an extracurricular (school-based) or a community club setting) captured in the School Sport Survey ${ }^{12}$ was used as the benchmark for grading. Of children aged 7 to 16 years old, $48 \%$ took part in sport on 3 or more occasions a week. ${ }^{12}$ These data showed an upward trend from $27 \%, 40 \%$, and $48 \%$ in 2011, 2013, and 2015, respectively. Moreover, similar proportions of primary (49\%) and secondary (48\%) age school children took part in sport on 3 or more occasions a week although more boys (52\%) met the criteria than girls (44\%). Even though there were differences by age (52\% of 10 - to 12 -year-olds, $45 \% 14$ - to 16 -year-olds), ethnicity (White 49\%, Mixed Race 52\%, Black 52\%, Asian 36\%, Other $39 \%$ ), disability (40\% with a disability, $49 \%$ without), and socioeconomic status (43\% low, 54\% high), there was an overall increase in the proportion of children who took part in sport on 3 or more occasions a week between 2013 and 2015 for boys and girls. ${ }^{12}$ The Further Education Sport Survey of students aged 16 and over also showed that $49 \%$ took part in sport 3 or more times per week, in any setting. ${ }^{13}$ Of these further education students $52 \%$ of $16-$ to 19 -year-olds and $37 \%$ of $20+$ year-olds met the criteria for taking part in sport. The RWG concluded that the increase in the proportion of children who took part in sport 3 or more times per week, and the finding that at least $40 \%$ of children in the vast majority of subgroups (gender, ethnicity, socioeconomic status and disability) met this criteria, was sufficient to warrant an increase in the grade from a $C$ - in 2014 to a $C$ in the 2016 Report Card.

\section{Outdoor and Active Play: C}

The grade for this indicator has not changed since 2014 although more data were available to support the 2016 grade. In the previous report card, 'use of the park' was used solely to establish the grade for this indicator. In the 2016 Report Card, the RWG agreed that the proportion of children using a variety of places for play should be considered. Data on the proportion of children and youth using 'streets near home or school' (43\%), 'park' (61\%), 'playground not

\section{Is Wales Turning the Tide on Children's Inactivity?}

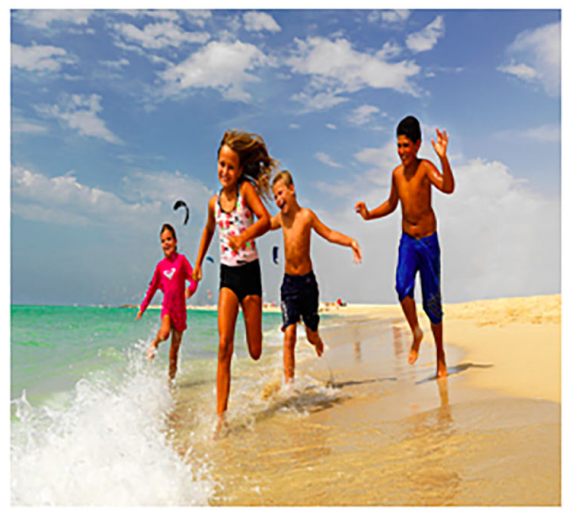

\section{ACTIVE HEALTHY KIDS WALES REPORT CARD 2016}

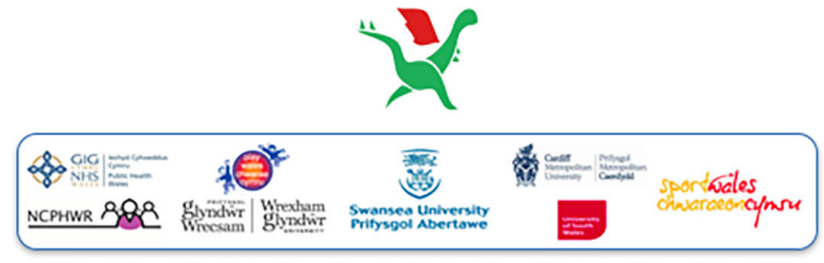

Figure 1 - Front cover of the Active Healthy Kids Wales 2016 Physical Activity Report Card. The cover story for the report card is: "Is Wales Turning the Tide on Children's Inactivity?" With over 100 beaches and over 750 miles of coastline in Wales, only $42 \%$ of children used the beach or sea at least once in the past year for exercise. ${ }^{12}$ Furthermore $90 \%$ of the population live within 30 minutes of the coast. Subsequently "turning the tide" captures meaning in the Welsh context and the aim of this Report Card is to "turn the tide on children's inactivity" and advocate national efforts to increase children's PA and reduce their sedentary time. Turning the tide on children's inactivity in Wales should be used to influence and inform policies and strategies, support structures, investments, and opportunities that help promote sound health, growth, and development in the nation's children and young people.

at school' (38\%), 'playing fields at school' (48\%), 'playing fields not at school' (50\%), and 'beach/sea' (42\%) for places of PA/play in the previous year were synthesized to give an overall proportion of $47 \%$ of children and youth using at least 1 of these places (School Sport Survey 2015). ${ }^{12}$ The Little Voices Shouting Out survey of children aged 7 to 11 years from across Wales reported that $18 \%$ spent 3 hours, $15 \%$ spent 4 hours, and $27 \%$ spent more than 4 hours playing outside on a normal day. ${ }^{19}$ The RWG concluded that $60 \%$ of children reporting spending $\geq 3$ hours outside playing was commensurate with a $C$ grade. 


\section{Active Transportation: $C$}

The largest available survey of active transportation in 7- to 16 -year-old children showed that $40 \%$ reported they either walked, cycled, scooted, or skated to school (School Sport Survey 2015). ${ }^{12}$ In a survey of parents of primary and secondary school children (National Survey for Wales 2014-15), ${ }^{16} 49 \%$ of primary school children and $35 \%$ of secondary school pupils walked to school regardless of distance. Data on children and young people aged 11 to 16 years showed that $32 \%$ (34\% boys, $31 \%$ girls) completed the main part of their journey to school by walking or cycling (HBSC Wales 2013/14). ${ }^{14}$ This data indicates that little has changed in the proportion of children and young people who actively traveled to school between the years 2006-2014. ${ }^{14}$ Data provided by Sustrans Wales, ${ }^{18}$ showed that $53.7 \%$ of children aged 7 to 16 years travel to school either by walking, cycling, or scooting/skating, and levels of children traveling to school by walking, cycling, or scooting/skating were consistent for the last 4 years of data collection. There was reassuring consistency across data sources for active transportation and this indicator was assigned a $C$ grade.

\section{Sedentary Behaviors: $D$ -}

On a weekday, $53 \%$ of children and young people spent $2+$ hours a day playing games on an electronic device, $64 \%$ spent $2+$ hours a day using an electronic device for purposes other than gaming, and $68 \%$ spent $2+$ hours a day watching entertainment on a screen. ${ }^{14}$ On the weekend, the proportion of children and young people who spent $2+$ hours a day playing games on an electronic device, using an electronic device for purposes other than gaming, and watching entertainment on a screen increased to $65 \%, 71 \%$, and $80 \%$, respectively. ${ }^{14}$ During weekdays, a higher proportion of boys spent 2 or more hours a day playing games on an electronic device and watching entertainment on a screen compared with girls. On the other hand, a higher proportion of girls spent more than 2 hours a day using an electronic device for purposes other than gaming. During the weekend, the gender differences in the proportion playing games on an electronic device and using an electronic device for purposes other than gaming remained the same as on weekdays, but there were similar proportions of both boys and girls spending more than 2 hours a day watching entertainment on a screen. Findings for both weekdays and weekends were consistent across all socioeconomic status, and findings for playing games on an electronic device were similar across age groups. Use of electronic devices for purposes other than gaming and watching entertainment increased with age for boys and girls. The RWG concluded that the increase in sedentary behavior on the weekend compared with weekdays and differences according to gender and age, justified the decrease from a grade $D$ in 2014 to a $D$-.

\section{Physical Literacy: Incomplete}

Wales has recently designed a national measure, the Dragon Challenge, for the physical competency domain of physical literacy for children aged 8 to 14 years. The Dragon Challenge has produced pilot data on children across Wales and initial results suggest that continued investment in developing skilled movements in children is required. ${ }^{22}$ The RWG decided to grade physical literacy as inconclusive based on the very recent development of the measurement tool for physical competency and the lack of available data on the other domains of physical literacy.

\section{Family and Peer Influence: $D+$}

Results from the Sport Wales Active Adult Survey (2014) found that $41 \%$ ( $46.3 \%$ males, $35.1 \%$ females) of the adult population took part in sport on 3 or more occasions per week, with the equivalent figure being 39\% in 2012. ${ }^{17}$ Findings from the Welsh Health Survey (2014), revealed that 3 out of 10 adults (38\% M, 23\% F) reported being physically active for $>30$ minutes on 5 or more days a week and there has been no increase in PA levels in adults since 2003..$^{15}$ Analysis of the School Sport Survey data ${ }^{12}$ found there is an increased probability of children taking part in sport on 3 or more occasions a week if their parents or friends are also involved in sport, with a $32 \%$ increased chance if their father, $27 \%$ increased chance if their mother, and $23 \%$ increased chance if their friends were also involved in sport. ${ }^{23}$ The same survey found that $27 \%$ of mothers, $36 \%$ of fathers, $39 \%$ of brothers, $31 \%$ of sisters, $35 \%$ of other family members, and $64 \%$ of children's friends (peers) took part in sport. ${ }^{12}$ Further, $18 \%$ and $26 \%$ of these children took part in sport with their mother and father, respectively. In addition, $25 \%$ of children took part with their brother, $19 \%$ with their sister, $20 \%$ with other family members, and $68 \%$ with their peers. ${ }^{12}$ Although there was little change in the participation in sport and PA levels of adults, the additional evidence demonstrating a parental/peer influence on children's participation in sport, which was absent in the 2014 Report Card, prompted the RWG to assign a grade of $D+$ compared with $D$ in the 2014 Report Card.

\section{School: $B$}

To grade this indicator, school physical education (PE) coordinators and children's responses in the School Sport Survey (2015) were synthesized. ${ }^{12}$ The survey provided data on percentage of schools that offer PA opportunities (excluding PE) to the majority of their pupils, percentage of schools with sufficient facilities/equipment to support pupils' PA and sport, percentage of schools where teachers were confident in delivering quality PE lessons, and percentage of children that believe PE lessons and school sport help them to have a healthy lifestyle. ${ }^{12}$ In total, $60 \%$ of primary schools and $80 \%$ of secondary schools provide a wide variety of extracurricular sport and dance opportunities to all pupils. This provision includes health, fitness and wellbeing activities, competitive activities, creative activities, and adventure activities. On average, primary schools provide 11 different extracurricular activities for pupils and secondary schools provide 16 . Physical education staff reported that $70 \%$ of primary and $62 \%$ of secondary schools agreed that the school had sufficient access to facilities to provide sport, and that $54 \%$ of primary and $50 \%$ of secondary schools owned sports facilities that were of high quality. Further, $73 \%$ of primary and $71 \%$ of secondary schools agreed that they had access to sufficient equipment to provide quality physical education and sport, and 77\% of primary and $85 \%$ of secondary schools reported teachers were confident in delivering quality physical education lessons. From the children's perspective, $62 \%$ of children reported that physical education lessons and school sport had really helped them to have a healthy lifestyle. In summary, schools were well resourced and the RWG assigned $B$ to this indicator.

\section{Community and the Built Environment: $C$}

Data from the National Survey for Wales found $54 \%$ and $38 \%$ of parents with a child aged 1 to 10 and 11 to 15 years, respectively, were satisfied with the play facilities in their local area. ${ }^{16}$ Of parents 
with a child aged 1 to 10 years who were dissatisfied, $83 \%$ reported a lack of suitable outdoor public places for their child to play, whereas $64 \%$ reported a lack of suitable indoor spaces. In addition, of the parents with a child aged 11 to 15 years who were dissatisfied, $77 \%$ cited a lack of suitable outdoor public places, $79 \%$ believed there was a lack of indoor public places, and $64 \%$ believed there were too few clubs or organized activities. Consultations with children, young people (aged 3 to 18+ years) and their parents showed that 'more places to play' was the highest priority (49\%) for children aged 3 to $7 .{ }^{20}$ Other common priorities for this age group were tackling poverty (29\%), improving child safety (28\%) and tackling bullying $(28 \%)$. For children aged 7 to 11 years, stopping bullying was the highest priority $(55 \%){ }^{20}$ The next 2 highest priorities for this age group were helping children and families in poverty $(47 \%)$, and making local areas safer for children $(41 \%)$. The most common priority $(53 \%)$ for young people aged 11 to 18 was tackling bullying. ${ }^{20}$ More than $40 \%$ of young people reported protecting children from violence and abuse at home, more facilities in the local area, and help for children and families in poverty as their highest priorities. Across all data reported, priorities did not vary substantially by age, gender or region for all age groups. The grade for Community and the Built Environment has decreased from a $B$ in the 2014 Report Card to a $C$ in 2016. This is due to the proportion of parents being dissatisfied with the play facilities in their local area.

\section{National Government Policy, Strategies, and Investments: $B$ -}

After extensive discussions, the RWG concluded that the grade would remain the same as in 2014. The grade was based on the findings that a) at governmental and quasi nongovernmental levels there is still evidence of leadership and commitment to provide PA opportunities for all children and youth; b) there are allocated funds and resources for the implementation of strategies to promote PA for all children and youth; c) the government has demonstrated progress through the key stages of public policy making; and d) Wales still has a number of key national and organizational policies that include $\mathrm{PA}^{21}$ and is making cross-government efforts to integrate them. With the exception of the proportion of children and young people who took part in sport on 3 or more occasions a week, the RWG also recognized that policies and strategies had not yet increased PA and that inequalities in PA remain.

\section{Discussion}

The results of the AHK Wales 2016 Report Card demonstrate that significant efforts need to be made to change children's inactive lifestyles and related choices. Further, using recommendations from the National Institute for Health and Care Excellence (NICE 2006), ${ }^{24}$ the best available evidence was synthesized and showed that the majority of children in Wales were insufficiently active (did not meet recommendation of at least 60 minutes of MVPA every day of the week), and spent excess time ( $>2$ hours) in sedentary behavior. 4,12,14,15 The most recent HBSC international report (2016) included summary statistics on PA and TV watching from 42 countries worldwide. ${ }^{2}$ These statistics demonstrate that Wales has one of the largest differences in number of boys who achieved 60 minutes of MVPA between high and low affluence groups. The differences for girls were not as marked and were more representative of other countries. A similar picture emerged for TV watching but there were negligible gender differences. Furthermore, Wales was placed in the bottom quartile of the 42 countries and had the lowest levels of PA in 11 to 15 year olds in the UK. ${ }^{2}$ International comparisons for TV watching ranked Wales in the top 5 for the proportion of children who watched 2 or more hours of TV on weekdays. ${ }^{2}$

Over the past 10 years, a significant effort has been made in Wales to influence children's PA and sport participation through programs such as "Dragon Sport" for primary and " $5 \times 60$ " programs for secondary age children. These programs have been developed, implemented and evaluated and found evidence that children's extracurricular participation had increased and the range of activities that schools offered had broadened. ${ }^{25,26}$ Moreover, Sport Wales in collaboration with Public Health Wales and the education sector have urged Government to give physical literacy the same emphasis in the school curriculum as literacy and numeracy. To a degree, these have had an effect where the number of children hooked on sport has increased steadily since 2011 although inequalities still exist.

For outdoor and active play, Wales has an influential national government organization that advocates for play (Play Wales). ${ }^{27}$ Wales was one of the first countries to integrate article 31 of the United Nations Convention on the Rights of the Child into policy, ${ }^{8}$ through its Children and Families (Wales) Measure 2010.28 Moreover, Play Wales has been referred to as "a highly focused, policyoriented NGO." 29 Further, the grading for outdoor and active play was encouraging compared with other countries. ${ }^{10}$

Walking and cycling has also received a policy boost in Wales. In 2013 the Welsh Government successfully introduced the 'Active Travel Act' onto its statute..$^{9}$ The increasing problem of children's sedentary time is worrying and we have recognized this in the shift of $D$ to $D$-. Community and the Built Environment also decreased from a $B$ in the 2014 Report Card to a $C$, although this was influenced by higher quality data that provided better insight into this indicator. Similar reasons explain the increase in grade given to family and peer influence that achieved a $D+$ compared with $D$ in 2014. Wales has a vibrant physical education program that is well resourced and links to community sport that are also well established, and also has a successful Healthy Schools Network that includes PA in its delivery portfolio. ${ }^{30}$ Similar to a number of developed countries, ${ }^{10}$ School achieved the highest grade of all the indicators $(B)$.

\section{Research Gaps}

The AHK Wales Report Card is produced every 2 years. There were significant gaps unveiled during the production of the AHK Wales 2014 Report Card and while many of these still remain, the AHK Wales 2016 process was built on a more complete data platform and a more robust approach by a more experienced RWG. The School Sport Survey ${ }^{12}$ captured data on over 115,000 children in $61 \%$ of primary and $87 \%$ of secondary schools in Wales, building on data from 110,000 children 2 years earlier. The HBSC international report was published in $2016^{2}$ and allowed detailed analysis of the 2013-14 data ${ }^{14}$ permitting trends to be analyzed and also data from Wales to be compared with other countries that used the same methodology. ${ }^{2}$ On the other hand, there are currently no large scale studies where PA or sedentary time have been measured objectively and inconsistency also exists across tools used to generate data on the 10 quality indicators. These issues are being partly addressed through the development of national indicators for sedentary time, PA, and physical literacy by a Wales' PA measurement and indicators group. The RWG also assigned a grade of Incomplete to the physical literacy indicator. Sport Wales and Swansea University have developed an objective measure of physical competency (Dragon 
Challenge) that will provide nationally representative data for use in future Report Cards.

One of the main challenges for the RWG was that most of the data available on children's PA and related behaviors were not aligned to quality indicators included in the Report Card. Further, the more interpretive indicators such as School, Family and Peer Influence, and National Government Policy, Strategies and Investments, and Community and the Built Environment required more synthesis of different levels and quality of data and expert opinion.

More recently, the University of South Australia used a Delphi process with 2 independent panels of international PA experts to produce 29 research priorities for the next decade. ${ }^{31}$ The 3 top research priorities were (1) effective and sustainable interventions to affect long-term increases in children's PA behavior; (2) the influence of policy and environmental changes on PA and sedentary behavior; and (3) prospective, longitudinal studies of the independent effects of PA and sedentary behavior on health. ${ }^{31}$ Wales should seek to address these research priorities. Future Report Cards will note whether these issues have been addressed. In the meantime this Report Card will serve as an advocacy tool to promote PA research in Wales and to generate a national evidence base to underpin future AHK Wales Report Cards.

\section{Recommendations to Improve the Grades}

Policy makers, practitioners, and educators should use the results of the AHK Wales 2016 Report Card to inform their decision processes. This is the second AHK Wales Report Card and, unlike more established cards, Wales is less familiar with using the results to influence factors affecting children's activity. PA promotion in Wales has received criticism for lacking leadership and joined up approaches across Government portfolios. ${ }^{32}$ This has resulted in fractures in strategy and delivery from national to local levels. Moreover, data provides the evidence to support the lack of impact on PA in Wales over the past decade. ${ }^{14,15}$ Wales requires a clearly articulated ambition, and this ambition requires an unbroken chain of policy-strategy-delivery-review to translate these factors into positive PA outcomes. Nonetheless the RWG and stakeholders fully expect to build momentum behind children's PA research and promotion as the Report Card becomes more established and informative. The RWG is following the lead given by Canada to provide evidence-guided recommendations to identify where investments of effort and resources can best influence the PA levels of children and youth (see for example, the dissemination, implementation, evaluation procedures for the Canadian 24-hour Movement Guidelines ${ }^{33}$ ). We are concerned that we have some of the lowest levels of PA and highest levels of sedentary behavior globally, ${ }^{2,14}$ and we will use these data to communicate and advocate approaches to improve this situation. Our overarching aim this year is to "turn the tide on physical inactivity" and make daily PA the social norm.

\section{Future Directions}

The Welsh Government has appointed a National Program Director for Physical Activity to work across cabinet portfolios and we hope that this will have an effect on PA at all levels including children. The "Getting Wales Moving" strategy will be launched in the summer of 2016 and prompt Welsh Government to develop a coordinated action plan based on the recommendations to resource an implementation and evaluation plan. The 'Transforming Public Health Strategy,' 'Communities First,' and 'Wellbeing of Future
Generations' (Wales) Acts have the potential to correct some of the fragmented approaches to promoting uptake of PA in the past.

The 2016 Global Summit on the Physical Activity of Children and the second meeting of the Active Healthy Kids Global Alliance provide valuable opportunities to learn from other countries that have a more established Report Card process or are in the early years of their respective Report Cards. In the future, AHK Wales will consult with researchers, knowledge users, and key stakeholders to reexamine the Report Card framework, indicators, and processes. This consultation will start with the AHK Wales 2016 Report Card launch and dissemination event on 25th July 2016 supported by an informative independent website (http://activehealthykidswales. com). Our future plans are to improve the current state of PA research and knowledge needs to enhance policies, programs, practices, products, communications and investments to increase PA of children and youth in Wales.

\section{Conclusion}

The AHK Wales 2016 Report Card results demonstrate a need for focused action and investment in promoting children's PA and reducing inactivity, sedentary time and their related behaviors. There has been significant investment at policy structure and delivery levels since 2007 yet these have had little effect on children's PA levels which remain one of the lowest out of all countries surveyed in the HBSC report (2016). ${ }^{2}$ On the other hand Wales has placed active transport on its statute, has a strong track record in children's right to play and is changing the school curriculum to include a significant pillar on well-being. Furthermore intersectoral collaboration has helped promote children's physical literacy and activity and include them as indicators in future national surveys. This Report Card urges greater investment in children's PA so that future generations receive the health and developmental benefits of PA and reduce the spiraling social and economic burden of inactivity.

\section{Acknowledgments}

The authors would like to thank the following individuals for their contributions to the AHK-Wales 2016 Report Card: Joanne Wallace, Anna Bryant, Sinead Brophy, Michael Sheldrick, and Luke Martin. This work was supported by a grant from Sport Wales, postgraduate support from the Swansea University Scholarship fund, and the National Centre for Public Health and Well Being Research Wales supported the launch. We also acknowledge the work of Owain Stratton and Angelica Hart Lindh (www.geoshepherds.com) for web site production and GIS mapping of data. Martin Standage, Michael Rosenberg, Lynne Boddy as external academic advisors, Nicola Thomas for supporting AHK-Wales 2016 meetings, Rebecca Cox (HBSC) for data analysis and presentation, and Liz Irvine and Masoumeh Minou for assisting with the public launch of the AHK-Wales 2016 Report Card. Roberts' views are those of the researcher, not necessarily the Welsh Government.

\section{References}

1. Sport Wales. http://gov.wales/docs/statistics/2008/081204sb702008 en.pdf. Accessed May 12, 2016.

2. Inchley J, Currie D, Young T, et al. Health Policy for Children and Adolescents, No. 7. Growing Up Unequal: Gender and Socioeconomic Differences in Young People's Health and Well-being. Health Behaviour in School-aged Children (HBSC) Study: International Report from the 2013/2014 Survey. Copenhagen, Denmark: WHO Regional Office for Europe; 2016. 
3. Tomkinson GR, Olds TS. Secular changes in pediatric aerobic fitness test performance: the global picture. Med Sport Sci. 2007;50:46-66. doi:10.1159/000101075 PubMed

4. Tyler R, Mackintosh K, Brophy S, et al. Swan-Linx: Fitness Fun Day Report - Swansea Schools 2015. http://www.swansea.ac.uk/staff/ academic/engineering/strattongareth/. Accessed May 23, 2016.

5. Bailey L. Child Measurement Programme for Wales 2013/14. Wales: Public Health Wales NHS Trust; 2015. http://www.wales.nhs.uk/ sitesplus/888/page/67795, Accessed May 12, 2016.

6. Sport Wales. Our Vision. http://sport.wales/about-us/about-sportwales/our-vision.aspx. Accessed May 12, 2016.

7. Sport Wales. Physical Literacy. http://physicalliteracy.sportwales.org. uk/en/. Accessed May 12, 2016.

8. United Nations Convention on the Rights of Children - Children's Rights in Wales. http://www.childrensrightswales.org.uk/. Accessed May 12, 2016.

9. Active Travel (Wales) Act 2013. http://www.legislation.gov.uk/ anaw/2013/7/contents/enacted. Accessed May 23, 2016.

10. Tremblay MS, Gray CE, Akinroye KK, et al. Physical activity of children: a global matrix of grades comparing 15 countries. J Phys Act Health. 2014;11(1):113-125. PubMed doi:10.1123/jpah.2014-0177

11. Whitehead M. Definition of physical literacy and clarification of related. ICSSPE Bull J Sport Sci Phys Educ. 2013;65:28-33.

12. Sport Wales. School Sport Survey 2015. http://sportwales.org.uk/ research--policy/surveys-and-statistics/school-sport-survey.aspx. Accessed November 30, 2015.

13. Sport Wales. Further Education Sport Survey 2015. http://sport.wales/ media/1667685/further_education_sport_survey_-_state_of_the_ nation_2015_english_final_2.pdf. Accessed November 30, 2015.

14. Health Behaviour in School-aged Children Wales Survey 2013/14. http://gov.wales/statistics-and-research/health-behaviour-school-agedchildren/?lang=en. Accessed October 27, 2015

15. Welsh Health Survey 2014: http://gov.wales/statistics-and-research/ welsh-health-survey/?lang=en. Accessed November 30, 2015.

16. National Survey for Wales. 2014/15. http://gov.wales/statistics-andresearch/national-survey/?tab=current\&lang=en. Accessed November 30, 2015.

17. Sport Wales. Active Adult Survey 2014. http://sport.wales/researchpolicy/surveys-and-statistics/active-adults-survey.aspx. Accessed March 3, 2016

18. Sport Wales. Sustrans Cymru. http://www.sustrans.org.uk/wales. Accessibility verified May 23, 2016.

19. Little Voices Shouting Out Report 2015. https://www.swansea.ac.uk/ media/Little\%20Voices\%20Report.pdf. Accessed March 3, 2016
20. Beth Nesa? I What Next? 2015. http://www.childcomwales.org.uk/ publications/publications-list/. Accessed March 3, 2016

21. Physical Activity and Nutrition Wales. Welsh Policy and Strategy. http://www.physicalactivityandnutritionwales.org.uk/page. cfm?orgid=740\&pid=43282. Accessed May 23, 2016.

22. Dragon Challenge Circuit Video. https://www.youtube.com/ watch?v=lSPLtwDrgRM. Accessed May 23, 2016.

23. Sport Wales. School Sport Survey 2015. Increased probability of being 'hooked on sport'. http://sport.wales/media/1194537/theme2. pdf. Accessibility verified May 23, 2016.

24. National Institute for Health and Clinical Excellence Website. Available at: https://www.nice.org.uk/. Accessibility verified May 23, 2016.

25. Sport Wales. Review of Dragon Sport 2010. http://sport.wales/ research-policy/tools-and-resources/publications.aspx\#2010pub. Accessed August 11, 2016.

26. Sport Wales. 5x60 Case Studies 2011. http://sport.wales/researchpolicy/tools-and-resources/publications.aspx\#2011pub. Accessed August 11, 2016.

27. Play Wales Website. http://www.playwales.org.uk/eng/. Accessed May 23, 2016

28. Welsh Government. The Children and Families (Wales) Measure 2010 (Commencement No. 5). Order. 2012;2012. Available at http://originwww.legislation.gov.uk/wsi/2012/2453/contents/made Accessed May 23, 2016

29. Croke R, Williams J, eds. Wales UNCRC Monitoring Group. Report to the United Nations Committee on the Rights of the Child. Swansea, Wales: The Wales Observatory on Human Rights of Children and Young People; 2015.

30. Welsh Network of Healthy School Schemes Website. http://www. wales.nhs.uk/sitesplus/888/page/82249\#introduction. Accessed May 23, 2016.

31. Gillis L, Tomkinson G, Olds T, et al. Research priorities for child and adolescent physical activity and sedentary behaviours: an international perspective using a twin-panel Delphi procedure. Int J Behav Nutr Phys Act. 2013;10:112. PubMed doi:10.1186/1479-5868-10-112

32. Wales Audit Office. Increase Physical Activity 2007. http://www. wales.nhs.uk/documents/physical_activity_eng.pdf. Accessed August 11,2016

33. Tremblay MS, Carson V, Chaput JP, et al. Canadian 24-hour movement guidelines for children and youth: an integration of physical activity, sedentary behaviour, and sleep 1. Appl Physiol Nutr Metab. 2016;41(6):311-327. doi:10.1139/apnm-2016-0151 